\title{
Modulation of the intestinal microbiota and the metabolites produced by the administration of ice cream and a dietary supplement containing the same probiotics
}

\author{
Vivian Cristina da Cruz Rodrigues ${ }^{1}$, Ana Luiza Rocha Faria Duque ${ }^{2}$, Luciana de Carvalho Fino ${ }^{1}$, \\ Fernando Moreira Simabuco ${ }^{1}$, Adilson Sartoratto ${ }^{3}$, Lucélia Cabral ${ }^{4}$, Melline Fontes Noronha ${ }^{5}$, \\ Katia Sivieri ${ }^{2}$ and Adriane Elisabete Costa Antunes ${ }^{1 *}$ \\ ${ }^{1}$ School of Applied Sciences (FCA), State University of Campinas, Limeira, SP 13484-350, Brazil \\ ${ }^{2}$ Department of Food and Nutrition, School of Pharmaceutical Sciences, São Paulo State University (UNESP), Araraquara, \\ SP 14800-903, Brazil \\ ${ }^{3}$ Division of Organic and Pharmaceutical Chemistry, Pluridisciplinary Center for Chemical, Biological and Agricultural \\ Research (CPQBA), State University of Campinas, Paulinia, SP 13148-218, Brazil \\ ${ }^{4}$ Brazilian Biorenewables National Laboratory (LNBR), Brazilian Center for Research in Energy and Materials (CNPEM), \\ Campinas, SP 13083-970, Brazil \\ ${ }^{5}$ Genome Research Division, Research Informatics Core, Research Resource Center, University of Illinois at Chicago, Chicago, \\ IL 60612, USA \\ (Submitted 7 November 2019 - Final revision received 13 January 2020 - Accepted 21 February 2020 - First published online 6 March 2020)
}

\section{Abstract}

The aim of the present work was to compare the capacity to modulate the intestinal microbiota and the production of metabolites after $14 \mathrm{~d}$ administration of a commercial dietary supplement and a manufactured ice cream, both containing the same quantity of inulin and the same viable counts of Lactobacillus acidophilus LA-5 and Bifidobacterium animalis BB-12, using the Simulator of the Human Intestinal Microbial Ecosystem (SHIME ${ }^{\circledR}$ ) model. Samples of the colonic contents were evaluated microbiologically by real-time quantitative PCR (qRT-PCR) and next-generation sequencing and chemically by the production of SCFA (acetate, propionate and butyrate) and ammonium ions $\left(\mathrm{NH}_{4}^{+}\right)$. Statistical analyses were carried out for all the variables using the two-way ANOVA followed by the Tukey multiple comparisons test $(P<0 \cdot 05)$ for metabolite production, qRT-PCR and the bioinformatics analysis for microbiota diversity. Dietary supplement and ice cream were able to deliver the probiotic $L$. acidophilus and B. animalis to the simulated colon and modulate the microbiota, increasing beneficial micro-organisms such as Bifidobacterium spp., Bacteroides spp. and Faecalibacterium spp. for dietary supplement administration, and Lactobacillus spp. for ice cream supplementation. However, the ice cream matrix was probably more favourable for the maintenance of the metabolic activity of the probiotics in the $\mathrm{SHIME}^{\circledR}$ model, due to the larger amounts of acetate, propionate, butyrate and ammonium ions obtained after $14 \mathrm{~d}$ of supplementation. In conclusion, both ways of probiotic supplementation could be efficient, each with its own particularities.

Key words: SHIME ${ }^{\circledR}$ Lactobacillus acidophilus: Bifidobacterium animalis: Fatty acids: Ammonia

The intestinal microbiota is a complex community composed of several micro-organisms ${ }^{(1,2)}$ that acts on functions such as modulation of the intestinal epithelium, strengthening of intestinal integrity $^{(3,4)}$, prevention of pathogenic colonisation ${ }^{(2,5,6)}$, energy gathering and storage ${ }^{(7)}$, regulation of immunity ${ }^{(5,8)}$, synthesis, extraction and absorption of metabolites and nutrients, digestion regulation and signalling of cell pathways ${ }^{(2)}$.

The composition of the microbiota varies amongst individuals due to intrinsic and extrinsic factors such as different life stages, genetics, lifestyle, eating habits, ethnicity, frequency of physical activity, culture and environmental habits ${ }^{(2,9)}$. In order to modulate the microbiota, strategies such as the insertion of probiotics and/or prebiotics into products can be adopted.

Probiotics generally promote health benefits for their consumers by competing with other potentially putrefying or pathogenic bacteria for adhesion sites and nutrients ${ }^{(10-12)}$. In addition, these micro-organisms can modulate the immune system ${ }^{(13,14)}$, are able to improve the nutritional value of food and nutrient

Abbreviations: CFU, colony-forming units; SHIME®, Simulator of the Human Intestinal Microbial Ecosystem.

* Corresponding author: Adriane Elisabete Costa Antunes, email adriane.antunes@fca.unicamp.br 
bioavailability and may help to decrease intestinal inflammatory processes and blood pressure ${ }^{(15-17)}$. However, these effects are specific to each host and depend on the strain selected, making it impossible to attribute the same health benefits to all bacteria classified as probiotics ${ }^{(18-20)}$

The main products chosen by industry for probiotic delivery are yogurt and fermented milks ${ }^{(21)}$, but other non-dairy and dairy foods such as ice creams and even supplements have been tested to diversify the consumption of probiotic products ${ }^{(21,22)}$. Although ice cream is an occasional foodstuff ${ }^{(23)}$, it is one of the products that, besides being nutritious, has great potential as a functional vehicle for the addition of bioactive, probiotic and prebiotic compounds, due to its neutral $\mathrm{pH}$ and low storage temperature ${ }^{(21)}$. Dietary supplements represent another product commonly used for probiotic delivery with a view to supplementing the diet (oral ingestion) ${ }^{(24)}$.

In vivo experiments are ideal and more representative to evaluate the administration of pro- and prebiotics, although the cost, time and ethics may be a limiting factor ${ }^{(25)}$. Alternatively, the use of in vitro models may be able to simulate the microbiological and physiological processes of the gastrointestinal tract and, when associated with molecular analyses, may facilitate the understanding of the functioning of different systems or pathways, as well as complementing in vivo studies, with the advantage of the possible control of several parameters ${ }^{(25,26)}$.

Amongst the different models, in vitro fermentative models are excellent tools to assess how the microbiota and gastrointestinal environment can be altered by distinct variables (diet, drugs, pathogens and toxic compounds) ${ }^{(27)}$. The models can basically be divided into Batch Fermentation Models, such as the VTT One Compartment Fermentation Model ${ }^{(28)}$, and Dynamic Fermentation Models, represented by the TNO In Vitro Model of the Colon ${ }^{(29)}$, the Simulator of the Human Intestinal Microbial Ecosystem (SHIME $)^{(30)}$ and the Computer-Controlled Multicompartmental Dynamic Model of the Gastrointestinal System SIMGI (SIMulatorGastro-Intestinal) ${ }^{(31)}$.

The SHIME ${ }^{\circledR}$ is one of the dynamic models which is useful for studying the composition and function of the intestinal microbiota. The human digestion is simulated in an environment in which the numbers and proportions of the different microorganisms and the conditions such as temperature, $\mathrm{pH}$, inoculum and retention time are all similar to those of the human organism $^{(26,32)}$.

The aim of the present study was to evaluate an ice cream and a commercial dietary supplement as vehicles for probiotic delivery and compare them using the SHIME ${ }^{\circledR}$, analysing the modulation of the microbiota, SCFA and the production of ammonia.

\section{Experimental methods}

\section{Dietary supplement}

The commercial dietary supplement Bidrilac ${ }^{\circledR}$ (Chr-Hansen) was used, containing the micro-organisms Lactobacillus acidophilus LA-5 and Bifidobacterium animalis subsp. lactis BB-12, plus inulin, mannitol, silicon dioxide and vanilla flavour. The sachet was purchased from a local pharmacy, dissolved in $100 \mathrm{ml}$ of water and used shortly after dissolution. Each sachet $(1 \mathrm{~g})$ contained $9 \log$ colony-forming units (CFU)/g of LA-5, $10 \log _{10}$ $\mathrm{CFU} / \mathrm{g}$ of BB-12 and $0 \cdot 22 \mathrm{~g}$ of inulin ${ }^{(33)}$.

\section{Ice cream production}

The probiotic ice cream was produced using the Cuisinart Commercial Quality Compressor Ice Cream \& Gelato Maker, located in the School of Applied Sciences (Unicamp). The ice cream was manufactured to contain the same viable counts of the probiotics found in the commercial dietary supplement and also the same quantity of inulin, in order to enable a reliable comparison between them. The ingredients and quantities used to prepare $100 \mathrm{~g}$ of ice cream were: $25 \mathrm{~g}$ of whole milk powder (Nestlé), $0.73 \mathrm{~g}$ of inulin (GR of vegetable origin, Beneo-Orafti), $7 \mathrm{~g}$ of sucrose (Caravelas), $1 \mathrm{~g}$ of vanilla extract (Dr Oetker), $20 \mathrm{~g}$ of dairy cream (Shefa), $1 \mathrm{~g}$ of emulsifier (Emustab, Duas Rodas) and the probiotic cultures. The same probiotic strains found in the commercial supplement (L. acidophilus LA-5 and B. animalis subsp. lactis BB-12) were purchased from ChrHansen as a commercial direct vat set to produce the ice cream. These probiotics $(0 \cdot 2 \mathrm{~g}$ of BB-12 and $0 \cdot 16 \mathrm{~g}$ of LA- 5$)$ were previously activated in milk $\mathrm{k}^{(33,34)}$ and added manually at the end of the ice cream making process.

The total amount administered for both supplementation forms was $3.08 \mathrm{~g}$ of inulin and $10 \log \mathrm{CFU}$ of L. acidophilus and $11 \log$ CFU of $B$. animalis. When the prebiotic and probiotic were delivered by dairy food, a total of $420 \mathrm{~g}$ of ice cream was administered.

\section{Physicochemical analysis of the ice cream}

The ice cream was characterised by its total solid content, titratable acidity, $\mathrm{pH}$ and proximate composition. All analyses were carried out in triplicate.

The total solids, titratable acidity and $\mathrm{pH}$ were determined following the methodology described by IAL ${ }^{(35)}$ and the proximate composition according to the AOAC methods. The moisture content was determined in a drying oven at $105^{\circ} \mathrm{C}$ for 6 to $8 \mathrm{~h}$ and the ash content in a muffle furnace at $550^{\circ} \mathrm{C}$ for $8 \mathrm{~h}$. The protein content was determined using the micro-Kjeldahl method, where the crude protein was calculated by multiplying the $\mathrm{N}$ content by the factor 6.38 for dairy products ${ }^{(36)}$. The lipid content was quantified using the Mojonnier method ${ }^{(37)}$ and the total carbohydrates calculated by difference.

\section{Simulated digestion in the dynamic colonic model}

The $\mathrm{SHIME}^{\circledR}$ was used to simulate the human digestion process. The SHIME $^{\circledR}$ reactor is computer-controlled and consists of five closed compartments representing the stomach, small intestine, ascending colon, transverse colon and descending colon ${ }^{(38)}$. The simulator located at the School of Pharmaceutical Sciences (Food Science and Nutrition Department, Unesp, Araraquara, Brazil) was adapted for this study, where the transverse and descending colons were replaced by the triplicate of the ascending colon, aiming to obtain replicates of the experiment for a statistical comparison of the data.

The volumetric capacity, $\mathrm{pH}$, temperature $\left(37^{\circ} \mathrm{C}\right)$ and retention time $(24 \mathrm{~h})$ were controlled ${ }^{(39)}$, and the last three 
compartments were stirred with a magnetic stirrer throughout the whole process. Anaerobiosis of the system was achieved by the addition of $\mathrm{N}$, and the $\mathrm{pH}$ value corrected in each vessel using hydrochloric acid or sodium hydroxide accordingly, to be in the range from $5 \cdot 6$ to $5.9^{(38,39)}$.

The compartments were colonised with faeces from eight healthy male volunteers from the Army Cadet Preparatory School (EsPCEx), aged between 18 and 22 years old (Research Ethics Committee, No. 2.845.537). According to the procedures presented by Duque et $a l .{ }^{(40)}$, as adapted from Possemiers et $a l .{ }^{(32)}$, the samples were homogenised (all the collected samples containing different amounts were mixed) and $40 \mathrm{~g}$ diluted in $200 \mathrm{ml}$ of phosphate buffer ( $\mathrm{pH} 6.5$ ), composed of $7.08 \mathrm{~g} / \mathrm{l}$ of monosodium phosphate (Synth), $5.98 \mathrm{~g} / 1$ of disodium phosphate (Synth) and $1 \mathrm{~g} / \mathrm{l}$ of sodium thioglycolate (Merck). This mixture was then homogenised in a stomacher and centrifuged at $3000 \boldsymbol{g}$ for $15 \mathrm{~min}$. The supernatant was collected, and $10 \mathrm{ml}$ was added to each of the last three compartments together with $500 \mathrm{ml}$ of sterile feed medium, which is a carbohydrate-based medium with an important role in the environmental adaptation and inoculum growth, with the formation of a stable and representative community ${ }^{(38)}$.

The feed medium used in SHIME ${ }^{\circledR}$ was prepared in distilled water, consisting of $3 \mathrm{~g} / \mathrm{l}$ starch (Maisena, Unilever Brazil), $2 \mathrm{~g} / \mathrm{l}$ pectin (Sigma-Aldrich), $4 \mathrm{~g} / 1$ of gastric mucin type II swine (Sigma-Aldrich), $1 \mathrm{~g} / 1$ xylan (Megazyme), $1 \mathrm{~g} / \mathrm{l}$ peptone (Kasvi), $1 \mathrm{~g} / \mathrm{l}$ of arabinogalactan (Sigma-Aldrich), $0.4 \mathrm{~g} / \mathrm{l}$ glucose (Synth), $3 \mathrm{~g} / \mathrm{l}$ yeast extract (Kasvi) and $0.5 \mathrm{~g} / \mathrm{l}$ of L-cysteine (Sigma-Aldrich) ${ }^{(39)}$. In order to simulate the duodenum conditions, an artificial pancreatic juice composed of $12.5 \mathrm{~g} / \mathrm{l}$ sodium bicarbonate (LS Chemicals), $6 \mathrm{~g} / \mathrm{l}$ Ox Bile (Sigma-Aldrich) and $0.9 \mathrm{~g} / \mathrm{l}$ pancreatin (Sigma-Aldrich) was added to the second reactor $^{(39)}$.

\section{Experimental protocol}

The experimental period in the SHIME ${ }^{\circledR}$ reactor lasted 7 weeks. For the microbiota stabilisation period (control), the feed medium $(240 \mathrm{ml})$ and pancreatic juice $(60 \mathrm{ml})$ were inserted into the system and allowed to stabilise for $14 \mathrm{~d}^{(39,41)}$. After 2 weeks of stabilisation, the first treatment was administered and allowed to develop for $14 \mathrm{~d}$. The treatment consisted of $1 \mathrm{~g}$ of dietary supplement dissolved in $100 \mathrm{ml}$ of sterile filtered water and $140 \mathrm{ml}$ of feed medium. Between treatments, a 7-d washout period was applied, where only the feed medium $(240 \mathrm{ml})$ and pancreatic juice $(60 \mathrm{ml})$ were added. After the washout, the second treatment $(14 \mathrm{~d})$ started, with the addition of $30 \mathrm{~g} / \mathrm{d}$ of the probiotic ice cream (corresponding to half of the recommended portion for daily consumption, according to RDC 359, Brazil $\left.{ }^{(23)}\right), 70 \mathrm{ml}$ of sterile filtered water and $140 \mathrm{ml}$ of feed medium. The experiment was carried out in biological triplicate.

\section{Metabolites production}

After the simulated digestion, the samples from the colon compartment ( $n$ 6) were collected and stored at $-20^{\circ} \mathrm{C}$ and the ammonium ions $\left(\mathrm{NH}_{4}^{+}\right)$quantified according to Bianchi et al $^{(42)}$ using a specific ion meter (model 710A, Orion) coupled to a selective ammonia ion electrode (model 95-12, Orion).
Briefly, the electrode was calibrated with different standards (10, 100 and 1000 parts per million) (Thermo - Orion), and then $0 \cdot 2 \mathrm{ml}$ of solution added to $10 \mathrm{ml}$ of each sample for adjustment of the ionic strength in order to make the readings. The readings were carried out in triplicate at a temperature of $25^{\circ} \mathrm{C}$ with constant stirring. The results were divided by the molar mass of the ammonium ion (18.04) and expressed in mmol/l.

The SCFA were analysed according to the protocol adopted by Duque et al. ${ }^{(40)}$, with modifications. The samples ( $n 3$, second week of the colon reactors) were centrifuged (14000 $\mathrm{g}, 5 \mathrm{~min}$ ), and $2 \mathrm{ml}$ of the supernatant was stored for analysis. Analytical curves were constructed from stock solutions of the acids of interest (acetic, propionic and butyric). The samples were filtered through Millex® filters $(0.45 \mu \mathrm{m})$ into flasks and then injected into an Agilent HP-6890 gas chromatograph equipped with an Agilent model HP-5975 mass-selective detector. A DBWAX capillary column $(60 \mathrm{~m} \times 0.25 \mathrm{~mm} \times 0.25 \mu \mathrm{m})$ was used under the following conditions: injector temperature $=220^{\circ} \mathrm{C}$, column $=35^{\circ} \mathrm{C}, 2^{\circ} \mathrm{C} / \mathrm{min}, 38^{\circ} \mathrm{C} ; 10^{\circ} \mathrm{C} / \mathrm{min}, 75^{\circ} \mathrm{C} ; 35^{\circ} \mathrm{C} / \mathrm{min}$, $120^{\circ} \mathrm{C}(1 \mathrm{~min}) ; 10^{\circ} \mathrm{C} / \mathrm{min}, 170^{\circ} \mathrm{C}(2 \mathrm{~min}) ; 40^{\circ} \mathrm{C} / \mathrm{min}, 170^{\circ} \mathrm{C}$ ( $2 \mathrm{~min}$ ), and detector $=250^{\circ} \mathrm{C}$. Helium was used as the carrier gas at a flow rate of $1 \mathrm{ml} / \mathrm{min}$.

\section{Real-time PCR}

The composition of the colonic intestinal microbiota was confirmed by real-time quantitative PCR. Samples were collected once a week, centrifuged (14000 g, $5 \mathrm{~min}$ ) and the pellet freeze-dried. The DNA of the samples was extracted using a QIAamp $^{\text {TM }}$ PowerFecal $^{\text {TM }}$ DNA Kit (QIAGEN Group) and quantified by nanodrop, adding to a mix composed of Power SYBR $^{\circledR}$ Green PCR Master Mix (Thermo Fisher Scientific), primers (forward and reverse) and ultrapure water free of endonucleases (DEPC-treated water). The readings were made using a StepOnePlus ${ }^{\mathrm{TM}}$ Real-Time PCR System (Thermo Fisher Scientific).

Specific primers for L. acidophilus and B. animalis were used for amplification of the DNA and used to prepare a standard curve composed of the DNA extracted from isolated cultures of the bacterial strains ${ }^{(43)}$. The primer sequences (Thermo Fisher Scientific) used for the quantification of L. acidophilus were forward: 5'-CTTTGACTCAGGCAATTGCTCGTGAAGGTATG-3' and reverse: 5'-CAACTTCTTTAGATGCTGAAGAAACAGCAGC TACG-3 ${ }^{\prime(44)}$, and for $B$. animalis forward: 5'-CACCAATG CGGAAGACCAG-3' and reverse: 5'-GTTGTTGAGAATCAG CGTGG-3 $3^{\prime(45)}$.

\section{Analysis of the microbiota diversity}

The diversity of the intestinal microbiota was analysed by next-generation sequencing (Neoprospecta Microbiome Technologies) where specific primers amplified the V3-V4 region of the $16 \mathrm{~S}$ ribosomal RNA (rRNA), 341F and $806 \mathrm{R}$ of $1 \mathrm{ng}$ of $\mathrm{DNA}^{(46,47)}$.

The PCR were carried out in triplicate using a Platinum Taq (Invitrogen USA) under the following conditions: $95^{\circ} \mathrm{C}$ for $5 \mathrm{~min}$, twenty-five cycles at $95^{\circ} \mathrm{C}$ for $45 \mathrm{~s}, 55^{\circ} \mathrm{C}$ for $30 \mathrm{~s}$ and $72^{\circ} \mathrm{C}$ per $45 \mathrm{~s}$, with a final extension of $72^{\circ} \mathrm{C}$ for $2 \mathrm{~min}$ for the first PCR (PCR 1). For the second PCR (PCR 2), the conditions were 
$95^{\circ} \mathrm{C}$ for $5 \mathrm{~min}$, ten cycles at $95^{\circ} \mathrm{C}$ for $45 \mathrm{~s}, 66^{\circ} \mathrm{C}$ for $30 \mathrm{~s}$ and $72^{\circ} \mathrm{C}$ for $45 \mathrm{~s}$, with a final extension of $72^{\circ} \mathrm{C}$ for $2 \mathrm{~min}$. After the last PCR, the samples were cleaned with AMPure beads (Beckman Coulter) ${ }^{(48)}$.

The sequencing libraries were prepared according to company technology, and the sequencing was carried out using the MiSeq platform (Illumina).

\section{Bioinformatical analysis}

FASTQC was used to carry out the initial quality control of the sequences and subsequently filtered with Trimmomatic (0.36). A total of 911717 raw sequences were submitted to quality control, and after filtering, 822120 sequences reads were obtained from all the samples (control, supplement, washout and ice cream) according to online Supplementary Table S1 (BioProject RPJNA573727). UCHIME2 was used to remove the chimeras ${ }^{(49)}$. The remaining sequences were processed using the Quantitative Insights into Microbial Ecology (QIIME version 1.9.0) software $^{(50)}$ and then grouped into operational taxonomic units with $97 \%$ identity by the QIIME's UCLUST method ${ }^{(51)}$. The bacterial 16S rRNA database, Greengenes (13_5 release) ${ }^{(52)}$ and RDPII classifier ${ }^{(53)}$ were selected to access the taxonomic annotation and PyNast used to align key sequences ${ }^{(54)}$. $\alpha$-Diversity was estimated using QIIME to generate rarefaction curves, Good's coverage, Chao1 richness ${ }^{(55)}$ and Shannon diversity ${ }^{(56)}$, and UniFrac was used to calculate the $\beta$-diversity metrics (weighted and unweighted measurements) ${ }^{(57,58)}$.

\section{Statistical analysis}

The results were computed, submitted to a normality test and reported as mean values with their standard errors, submitted to a one-way ANOVA, followed by the Tukey multiple comparisons test, with a significance level of $5 \%(P<0.05)$. The metabolites SCFA and ammonia, and the probiotic species L. acidophilus and B. animalis by real-time quantitative PCR analysis were obtained using the statistical software Prism 7.0 (Software MacKiev@ 1994-2016), and all data from relative abundance were performed using XLSTAT statistical and data analysis solution version 2019.4.2 (Addinsoft).

\section{Results and discussion}

\section{Physicochemical analysis of the ice cream}

According to Table 1 , the composition of the ice cream manufactured met the minimum criteria for the total solids (28\%), lipid (3.0\%) and protein $(2.5 \%)$ contents as recommended by the Brazilian Health Regulatory Agency ${ }^{(59)}$.

\section{Production of metabolites}

Table 2 shows the metabolites produced ( $\mathrm{mmol} / \mathrm{l})$ in the ascending colon during the in vitro experiment with different matrices.

The production of SCFA was greater with the administration of probiotic ice cream than with the dietary supplement. With the dietary supplement treatment, there were reductions in the amounts of acetate $(P<0.05)$ and propionate $(P>0.05)$ and an increase in the butyrate levels $(P>0.05)$. With the ice cream
Table 1. Titratable acidity, $\mathrm{pH}$ value, total solids and proximate composition of the ice cream ( $n$ 3) (Mean values with their standard errors)

\begin{tabular}{lcl}
\hline Parameter & Mean & SEM \\
\hline Titratable acidity (\%) & 0.46 & 0.01 \\
pH & 6.87 & 0.005 \\
Total solids (\%) & 35.56 & 0.37 \\
Moisture (\%) & 64.44 & 0.37 \\
Ash (\%) & 1.5 & 0.002 \\
Protein (\%) & 7.14 & 0.004 \\
Lipid (\%) & 15.20 & 0.45 \\
Total carbohydrate (\%) & 11.56 & 0.82 \\
\hline
\end{tabular}

treatment, the production of all acids was increased when compared with the corresponding washout period $(P<0.05)$ and this increase was only not significant for propionate $(P>0.05)$.

The dietary supplement was able to decrease the amount of acetate and propionate produced and only increased the butyrate production to a certain extent. This result is not common even in in vitro models involving prebiotics and probiotics, where the expected result is an increase of SCFA or no effect at all ${ }^{(60,61)}$. However, depending on the fermented fibre selected, some in vitro studies can demonstrate a reduction on specifics SCFA $^{(62)}$, such as the work presented by Yang et al. ${ }^{(63)}$ where the propionate amount was decreased after inulin and pectin treatments. Situations where there is a reduction on SCFA normally involve specific diseases such as inflammatory bowel disease $^{(64)}$ and allergy ${ }^{(65)}$.

Comparing the two products, all the SCFA were produced in larger quantities with the addition of the ice cream as the matrix. As indicated in the literature ${ }^{(66)}$, the percentage of acetate was higher than that of the other SCFA, reaching proportions in the ice cream of approximately 54:18:28 and in the supplement 59:23:18 for acetate, propionate and butyrate, respectively.

It is important to emphasise that not only the probiotic strains supplemented are able to produce SCFA but also other microorganisms belonging to the host gut microbiota. According to a review published by Feng et al. ${ }^{(67)}$, acetate is produced mainly via the Wood-Ljungdahl and acetyl-CoA pathways by enteric bacteria such as Bifidobacterium spp., Prevotella spp., Blautia bydrogenotrophica, Lactobacillus spp. and Bacteroides spp.; butyrate is produced via phosphotransbutyrylase/butyrate kinase routes and butyryl-CoA:acetate CoA-transferase routes by several Firmicutes such as Roseburia spp., Faecalibacterium prausnitzii, Eubacterium rectale, Clostridium leptum and Coprococcus catus and propionate is produced via the succinate, propanediol and acrylate pathways by Bacteroidetes and some Firmicutes such as Dialister spp., Phascolarctobacterium succinatutens, Roseburia inulinivorans, Salmonella spp., Veillonella spp. and Ruminococcus obeum. In the present work, it is possible to identify (Fig. 3(b)) some of the bacteria cited above and its distribution on the microbiota analysis through different treatments, for instance, change in the microbiota with ice cream addition increased the genus Dialister, a propionate producer that was also high after the treatment.

Chaikham \& Rattanasena(68) ${ }^{(6)}$ served similar results with probiotic low-fat ice creams (with Lactobacillus casei 01 and L. acidophilus LA5), obtaining an increase in SCFA when 
Table 2. SCFA and ammonia levels obtained in the Simulator of the Human Intestinal Microbial Ecosystem (SHIME®) reactor with the administration of the dietary supplement and ice cream*

(Mean values with their standard errors)

\begin{tabular}{|c|c|c|c|c|c|c|c|c|}
\hline \multirow[b]{3}{*}{ Experimental period } & \multicolumn{6}{|c|}{ SCFA } & & \\
\hline & \multicolumn{2}{|c|}{ Acetate $(\mathrm{mmol} / \mathrm{l})$} & \multicolumn{2}{|c|}{ Propionate $(\mathrm{mmol} / \mathrm{l})$} & \multicolumn{2}{|c|}{ Butyrate (mmol/l) } & \multicolumn{2}{|c|}{ Ammonia (mmol/l) } \\
\hline & Mean & SEM & Mean & SEM & Mean & SEM & Mean & SEM \\
\hline Control & $31 \cdot 24^{a}$ & 0.02 & $7 \cdot 23^{a}$ & 0.46 & $1.01^{\mathrm{a}}$ & 0.72 & $12 \cdot 86^{\mathrm{a}}$ & $1 \cdot 11$ \\
\hline Supplement & $11 \cdot 35^{\mathrm{b}}$ & 1.60 & $4 \cdot 35^{\mathrm{a}}$ & $1 \cdot 18$ & $3.44^{\mathrm{a}}$ & 0.25 & $8 \cdot 33^{b}$ & 1.00 \\
\hline Washout & $20.07^{b}$ & 2.46 & $6 \cdot 87^{a}$ & 1.02 & $6.77^{\mathrm{b}}$ & 0.55 & $12 \cdot 92^{\mathrm{a}}$ & 1.53 \\
\hline Ice cream & $30 \cdot 01^{a}$ & 3.05 & $10 \cdot 17^{a}$ & 0.48 & $15 \cdot 63^{a}$ & $1 \cdot 17$ & $15 \cdot 39^{a}$ & $2 \cdot 22$ \\
\hline
\end{tabular}

a,b Mean values within a column with unlike superscript letters were significantly different by the Tukey test $(P<0.05)$.

* Statistical analysis was carried out in pairs: control and supplement; washout and ice cream ( $n 3$ for SCFA; $n 6$ for ammonia).

compared with their controls (low-fat ice cream and washout periods). The modulating potential of the microbiota was also evaluated with prebiotics, as shown in the study by Van de Wiele et $a l .{ }^{(25)}$, which aimed to test the action of chicory inulin. The presence of inulin was able to increase the production of SCFA by $44 \%$ in 5 weeks of treatment, mainly of propionate and butyrate. Inulin has a bifidogenic effect, and this increase can be explained by the additional biomass of Bifidobacteria that are able to degrade inulin, producing more SCFA ${ }^{(25)}$. In the present work, the same amount of inulin was used to manufacture the probiotic ice cream as was found in the dietary supplement $(0.22 \mathrm{~g}$ per $1 \mathrm{~g})$. The amount required to claim an ice cream as a synbiotic food is $2 \cdot 5 \mathrm{~g}$ of inulin per serving portion. To avoid research bias between the ice cream and the dietary supplement, due to the quantity of inulin, the authors decided to calculate on the basis of $0.22 \mathrm{~g}$ of inulin per $30 \mathrm{~g}$ ice cream portion, which was the amount administered daily to the SHIME $^{\circledR}$ model. Thus, the ice cream manufactured in this research can be considered probiotic, but not synbiotic, due the low quantity of prebiotic added.

Similar to the results obtained with dietary supplement administration in the present study, the research presented by Bianchi et $a l{ }^{(42)}$ aimed to evaluate four fermented formulations based on aqueous extracts of soya and quinoa, using the SHIME ${ }^{\circledR}$ reactor. Of the four formulations tested: placebo, prebiotic (fructo-oligosaccharide), probiotic (L. casei Lc-01) and synbiotic, none was able to significantly increase the SCFA levels. These fatty acids are rapidly used up as a source of energy by the resident microbiota or colonocytes, soon after their formation, not allowing for significant accumulation ${ }^{(42,69,70)}$.

The same result is not observed in in vitro models where there is no colonocytes. In this type of research, for example, butyrate will be the end product from carbohydrates and proteins fermentation and will not be absorbed by gut mucosa (90-95\%) as normally it would in vivo, being quantified in its totality ${ }^{(71-73)}$. In addition, different factors, such as the presence of inorganic terminal electron receptors, individual preference of each species and the fermentation strategy of the micro-organism, amongst others, can interfere with the fatty acid formation process $^{(42,74)}$

The increase in the amount of SCFA is a desired effect, especially for intestinal health since these acids can bring benefits such as the inhibition of pathogenic micro-organisms and increase in mineral absorption by reducing the luminal $\mathrm{pH}$, stimulation of cellular proliferation in the epithelial tissue, increase of mucin production, modulation of metabolic activity such as intestinal homoeostasis, as well as the prevention and treatment of the metabolic syndrome, some types of cancer and intestinal disorders ${ }^{(75-78)}$.

Another metabolite of interest produced by the microbiota during fermentation is ammonia. The dietary supplement was able to significantly $(P<0.05)$ reduce ammonia production when compared with the control period. In the second treatment, the ice cream increased the amount of ammonia produced, although not significantly $(P>0.05)$. The levels recorded in the washout period were compatible with those of the control $(P>0 \cdot 05)$, proving that the reduction in the metabolite concentration was due to the administration of the supplement.

The ammonia reduction with administration of functional compounds such as probiotics and prebiotics has been demonstrated on other studies ${ }^{(79-81)}$. The decrease following the addition of the supplement can be the result of changes in the microbiota, where depending on nutrient availability, they may shift their metabolism favouring the saccharolytic over proteolytic fermentation routes ${ }^{(80,81)}$.

On the other hand, the discrete increase in the ammonia levels when ice cream was administered can be explained by the amount of protein present in the food matrix, an important fact since the degradation of this macronutrient will generate ammonia and other derivatives ${ }^{(82,83)}$. An experiment carried out with rats showed that increased milk protein intake was able to raise the amount of proteolytic metabolites in the colon $^{(84)}$. Some proteins can bind to other nutrients such as sugar, making them less digestible, but still fermentable by resident colon bacteria, which is a factor that can modify the host microbiota ${ }^{(85)}$.

Besides, the liberation of ammonium ions may be associated with the higher metabolic activity of some Bifidobacterium and Lactobacillus species which participate in deamination processes, according to Scott et al. ${ }^{(83)}$

Increased ammonia levels should be avoided, since depending on the amount, this metabolite can be toxic, being able to alter the cellular morphology of the colonocytes and act as a promoter of carcinogenesis in the intestinal tissue, increasing the risk of cancer development ${ }^{(82,86)}$. In addition, when in the bloodstream, it may be linked to hepatic encephalopathy, as well as neurotoxic effects ${ }^{(87-89)}$. 
Lactobacillus acidophilus

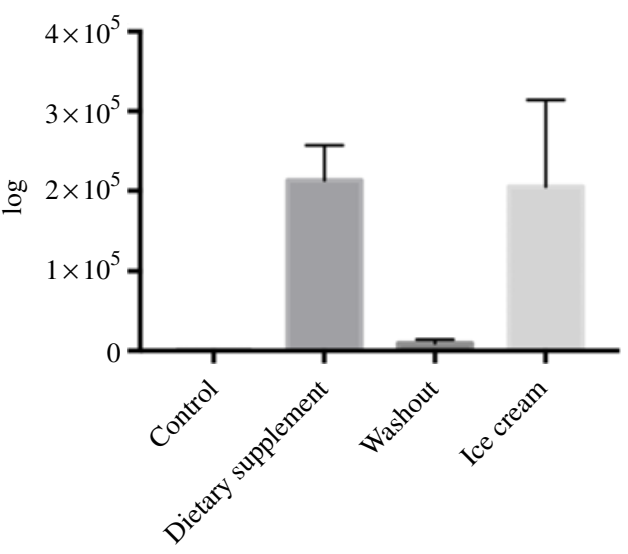

Bifidobacterium animalis

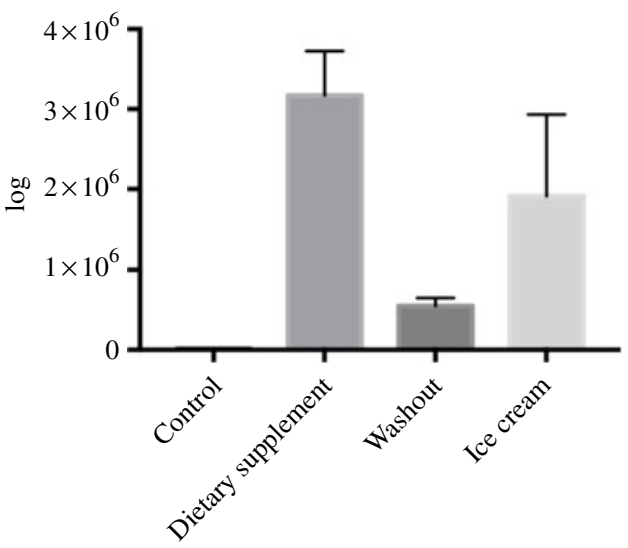

Fig. 1. Amounts of Lactobacillus acidophilus and Bifidobacterium animalis in the Simulator of the Human Intestinal Microbial Ecosystem (SHIME ${ }^{\circledR}$ reactor after administration of the dietary supplement and ice cream. Values are means $(n 6)$, with their standard errors represented by vertical bars. The statistical analysis was carried out in pairs, that is, control and supplement; washout and ice cream.

\section{Real-time quantitative $P C R$}

For the real-time quantitative PCR analysis, the concentrations of L. acidophilus and $B$. animalis were higher after administration of the strains in the SHIME system $(P<0 \cdot 05)$. Interestingly, regardless of the treatment used, the species remained in the same $\log \left(10^{5}\right.$ for L. acidophilus and $10^{6}$ for B. animalis). The lack of detection during the control period showed that the species were not originally from the host microbiota. Fig. 1 shows the real-time quantitative PCR analysis for quantification of the species L. acidophilus and B. animalis.

Similar results were also observed by Moens et al ${ }^{(72)}$ when administering a food supplement in the SHIME $^{\circledR}$ with mucosal compartments. They aimed to assess the influence of the probiotics (L. acidophilus, L. plantarum, L. rhamnosus and Enterococcus faecium) present in Symprove ${ }^{\mathrm{TM}}$ on the microbiota of three healthy humans during a 3-week period. As a result, some of the bacteria (L. acidophilus and L. rhamnosus) were not detected during the control period but could be identified after the initial administration as from 1 to 2 weeks. Rochet et al. ${ }^{(90)}$ also compared the administration of B. animalis DN-173010 in a fermented product and in the freeze-dried form, in a randomised study with healthy adults. They observed that for the freeze-dried B. animalis, DN-173010 cells were able to survive the digestion as well as the same strain in the fermented product and that the enzymatic activities were similar.

A previous phase of the research carried out by the present authors, compared the same dietary supplement and two dietary matrices (ice cream and fermented milk) to evaluate the viability and metabolic activity (by flow cytometry) after simulated digestion using a static model ${ }^{(33)}$ and observed higher viable cell counts, higher metabolic activity and less cellular damage when probiotics were added to the food matrices, as compared with the dietary supplement.

\section{Microbiota diversity analysis}

The identification of the microbiota in each experimental period was analysed by next-generation sequencing. Table 3 shows
Table 3. Number of Chao1 and Shannon indexes obtained for all the samples*

(Mean values with their standard errors)

\begin{tabular}{llllll}
\hline & \multicolumn{3}{c}{ Indexes } \\
\cline { 2 - 3 } & \multicolumn{2}{c}{ Chao1 } & & \multicolumn{2}{c}{ Shannon } \\
\cline { 2 - 3 } \cline { 5 - 6 } Experimental period & Mean & SEM & & Mean & SEM \\
\cline { 2 - 5 } Control & $4670.45^{\mathrm{a}}$ & 385.37 & & $6.71^{\mathrm{a}}$ & 0.09 \\
Dietary supplement & $3845.08^{\mathrm{b}}$ & 410.60 & & $6.18^{\mathrm{a}}$ & 0.48 \\
Washout & $4549.04^{\mathrm{a}}$ & 55.21 & & $6.72^{\mathrm{a}}$ & 0.24 \\
Ice cream & $3888.96^{\mathrm{b}}$ & 218.91 & & $6.55^{\mathrm{a}}$ & 0.24 \\
\hline
\end{tabular}

a,b Mean values within a column with unlike superscript letters were significantly different by the Tukey test $(P<0.05)$.

* Statistical analysis was carried out in pairs: control and supplement; washout and ice cream $(n 6)$.

the richness and diversity of the samples during the simulated digestion process.

According to Table 3, for both treatments (dietary supplement and ice cream), a non-significant reduction in the Shannon index was observed, suggesting no impairment of the microbial diversity. In conclusion, the products did not impair the microbial diversity. On the other hand, the total number of micro-organisms (richness) found in the triplicate of the ascending colon using the SHIME model was statistically reduced $(P<0.05$ for the dietary supplement and ice cream), as evidenced by the Chao index. This effect may have been due to the 'core microbiome' changes caused by both treatments.

During the whole experiment, four main phyla were identified: Actinobacteria, Bacteroidetes, Firmicutes and Proteobacteria (data not shown). According to Breban ${ }^{(91)}$, the predominant phyla in the intestinal microbiota are Bacteroidetes and Firmicutes, a result confirmed by the present study during the control, supplement treatment and washout periods. It was observed that the treatments were able to modify the microbiota, since different phylum arrangements were registered before and after each period. Administration of the supplement showed a tendency of decreasing Actinobacteria (from 25.4 to $16.9 \%)(P>0.05$ ) and a tendency of increasing the relative abundance of 
Firmicutes (from 34.5 to $42.5 \%)(P>0.05$ ). On the other hand, with the addition of ice cream, there was an increase of approximately $50 \%$ in the amount of Proteobacteria (from 5.4 to $9.9 \%$ ) $(P=0.09)$ and significant reduction in Bacteroidetes (from 27.8 to $19.8 \%)(P<0.05)$

A different outcome was observed with another milk matrix. Unno et $a l^{(92)}$ investigated the consumption of a probioticfermented milk (ABCT-BH starter culture containing L. acidophilus CSG, Lactobacillus brevis HY7401, Bifidobacterium longum HY8001, L. casei HY2782 and Streptococcus thermophilus, plus a dietary fibre mix and lactulose) for 3 weeks and observed an increase in Bacteroidetes and reduction in Firmicutes. The potential mechanisms of these changing outcomes caused by the administration of probiotics and prebiotics are a reduction in the $\mathrm{pH}$ of the lumen, bacteriocin production and nutrient competition, amongst others, that can favour the growth of specific micro-organisms ${ }^{(14)}$.

The administration of the probiotic products caused a pattern change in the percentage of relative abundance of the microbial orders during the different experimental periods (Fig. 2). A similarity between the control and washout periods was found during the experiment, with statistical predominance only for Bacteroidales and Clostridiales orders (online Supplementary Table S2). Comparing all the experimental periods, a statistical improvement $(P<0.05)$ of Coriobacteriales, Burkholderiales and Selenomonadales for the ice cream treatment was observed (online Supplementary Table S2 and Fig. 2). However, the relative abundance of microbiological orders was not statistically different due to dietary supplement administration. High abundance of Coriobacteriales was observed by Rettedal et al. ${ }^{(93)}$ after dairy drink treatment using rats model, a result similar to the presently found. The increase in Selenomonadales is probably due to the higher abundance of the genus Dialister observed.

A connection between the distribution of the samples and the relative abundance of micro-organisms during the different experimental periods is presented in Fig. 3 .

The results of the $\beta$-diversity analysis with different reactors (A, B and C) can be analysed by the principal coordinate analysis (Fig. 3(a)) and show that the samples corresponding to the treatment with ice cream (orange colour) were isolated from the other experimental periods (control in blue, dietary supplement in red and washout in green), demonstrating a different behaviour of the ice cream samples. This result was confirmed by the principal component analysis (Fig. 3(b)), which was able to explain about $96 \%$ of the data variation between the samples.

The principal component analysis allowed one to observe the similarity between the control and the washout and also that the treatment carried out with the dietary supplement favoured the elevation of beneficial micro-organisms, such as Bifidobacterium spp., Bacteroides spp. and Faecalibacterium spp., the first being one of the probiotic micro-organisms administered and a constituent of the dietary supplement itself,
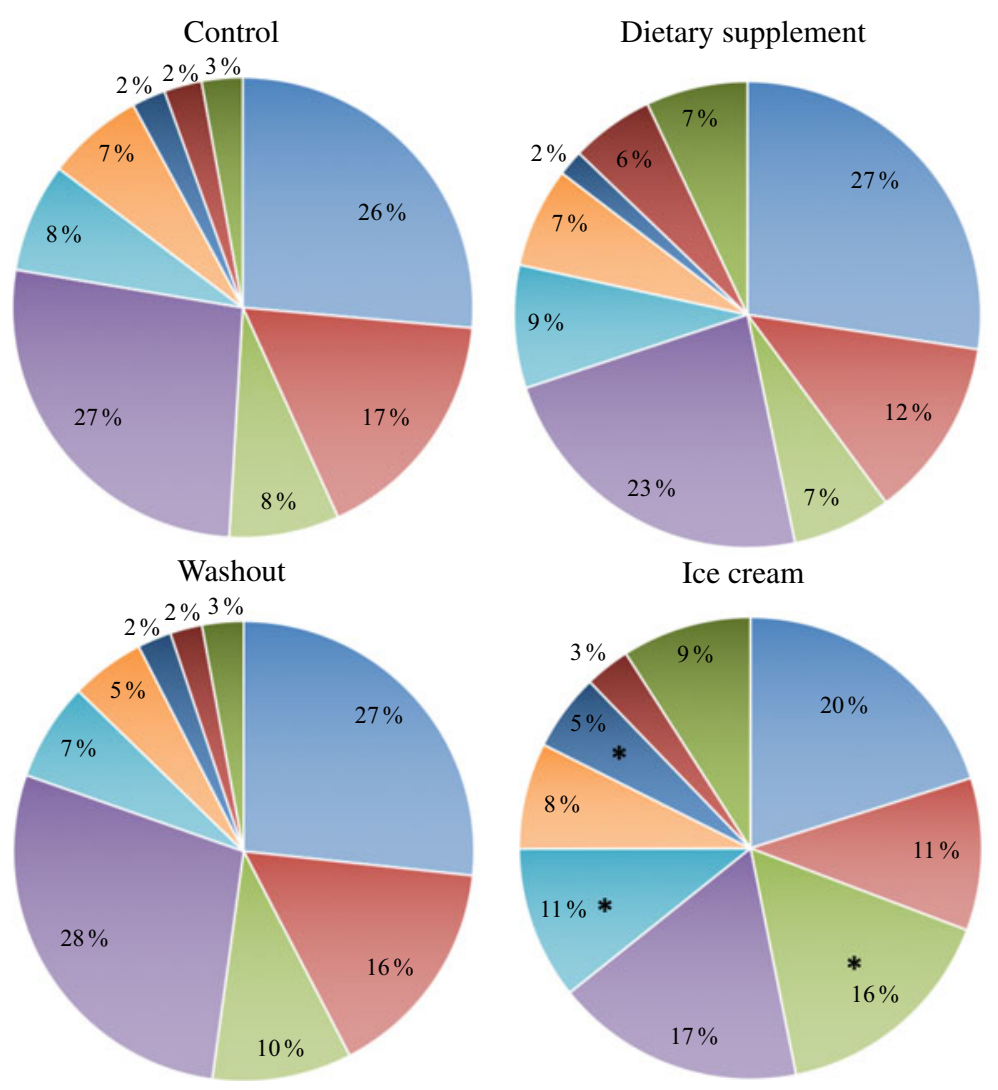

" Unassigned;other

- Burkholderiales

- Enterobacteriales

" Lactobacillales
" Coriobacteriales

" Clostridiales

" Selenomonadales

Fig. 2. Bacterial orders present in the microbiota with administration of the dietary supplement and ice cream. The statistical analysis was carried out for the four experimental periods (control, supplement, washout and ice cream). ${ }^{*} P<0.05$ ( $\left.n 6\right)$. 
(a)

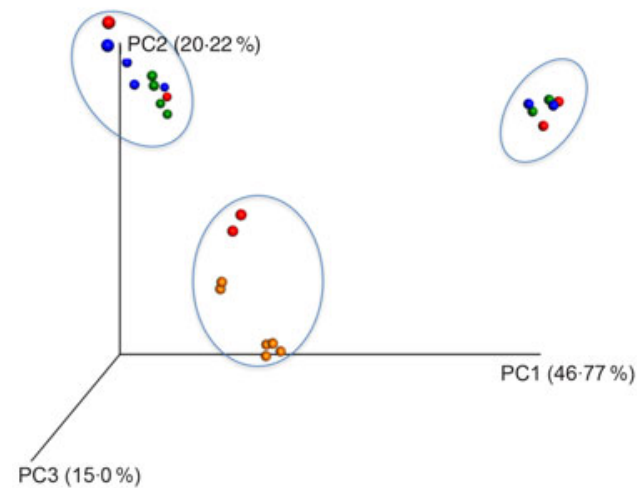

(b)

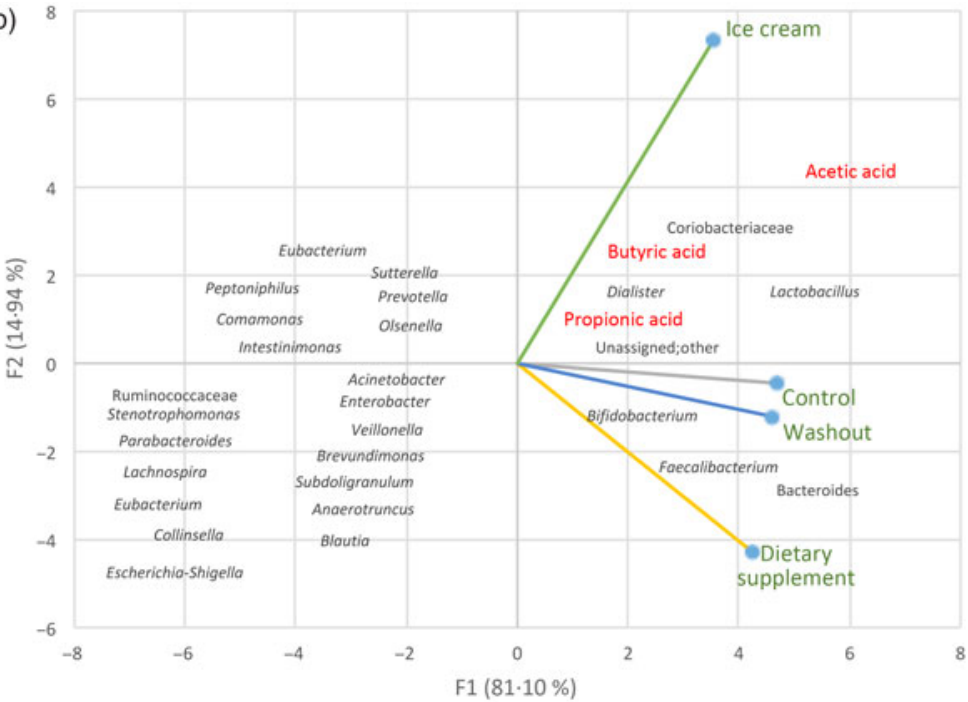

Fig. 3. (a) Principal coordinate analysis of jackknifed unweighted UniFrac distances for the $16 \mathrm{~S}$ ribosomal RNA (rRNA) gene sequence data; (b) principal component analysis diagram for the abundance of microbial taxa (mostly genus and family level) obtained using 16S rRNA gene sequencing correlated with SCFA production: (1)

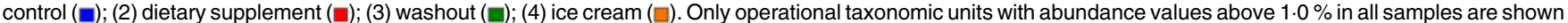
$(n 6)$.

and the last two being considered as next-generation probiotics. Next-generation probiotics, also known as live therapeutic products, are potentially probiotic species or genera not used by the food industry yet ${ }^{(94)}$. It is interesting to observe that many other SCFA product or bacteria (such as the genus Prevotella, Blautia, Eubacterium and Veillonella) were located at the left side of the principal component analysis graphic (Fig. 3(b)), so they were negatively related to baseline (control), washout and both treatments (dietary supplement and ice cream).

The genus Faecalibacterium (increased with dietary supplement) is one of the genera connected to a healthy microbiota $^{(95,96)}$, and in certain situations, a decrease in the amount of this genus can be connected with some diseases. Studies with $F$. prausnitzii showed its association with the inflammatory bowel disease, Crohn's disease and colorectal colitis $^{(97-99)}$, and also with symptoms of the irritable bowel syndrome ${ }^{(99,100)}$. This species is a butyrate producer, butyrate being the main source of energy for the colonocytes, has antiinflammatory properties ${ }^{(98,101)}$, and also affects immune regulation and the integrity of the epithelial barrier ${ }^{(102,103)}$. In susceptible individuals, a decrease in $F$. prausnitzii and the consequent reduction in butyrate can cause gut inflammation ${ }^{(104)}$. Due to its beneficial properties, mainly on gut-related diseases, studies have been carried out using $F$. prausnitzii as a possible biomarker to assist diagnostics and prognoses and also as a probiotic for treatment ${ }^{(101,104,105)}$.

Bacteroides spp. has been identified in low proportions on different conditions as type 2 diabetes mellitus ${ }^{(106)}$, obesity ${ }^{(107)}$, active major depressive disorder ${ }^{(108)}$ and Alzheimer's disease ${ }^{(109)}$ This type of study is important to enlighten different approaches and possible alternative ways of treatments and/or reduction of progress of specific diseases, such as the use of functional compounds as probiotics. O'toole et al. ${ }^{(110)}$ showed in a review that several studies have been made exploring the Bacteroides spp. as next-generation probiotics candidates targeting cancer, intestinal inflammation and heart diseases, among others. Also, Bacteroides fragilis has been used as possible probiotic treatment to behaviour symptoms for autism ${ }^{(111)}$.

On the other hand, supplementation of the $\mathrm{SHIME}^{\circledR}$ with ice cream (Fig. 3(b)) changed the microbiota pattern when compared with dietary supplement administration, control and washout periods, showing a strong correlation with the family Coriobacteriaceae and the genera Dialister and Lactobacillus. This treatment is more related to the production of the SCFA acetic, propionic and butyric, confirming the results obtained from the analysis of metabolites produced (Table 2). This finding also agrees with a paper previously published by our research group, where greater metabolic activity was observed for probiotics delivered by dairy matrices ${ }^{(33)}$.

The genus Dialister has four species, and some of these can be related to diseases (such as possible biomarkers or causes) ${ }^{(112,113)}$. However, this genus has also been linked to studies regarding its neuroactive potential in the treatment of depression, being considered a potential psychobiotic ${ }^{(114)}$. A psychobiotic can be defined as a live micro-organism that, when consumed in adequate amounts, can bring health benefits to individuals with psychiatric illnesses such as stress, depression and anxiety ${ }^{(115-117)}$.

In the present study, it was observed that a 14-d supplementation with an ice cream containing B. animalis, L. acidophilus and a small quantity of inulin promoted an increase in SCFA production, which can provide several physiological benefits. However, ice cream is a dessert with high energy density (rich in fat and sugar), and even the daily consumption of a functional ice cream should be treated with caution and continue to be an occasional foodstuff.

\section{Conclusion}

Both the dietary supplement and ice cream treatments were able to deliver viable probiotic cells. However, ice cream was 
possibly more effective for gut microbiota modulation because a significant increase of Coriobacteriales, Burkholderiales and Selenomonadales was observed. Moreover, a significant reduction in Bacteroidetes was also evident. Regarding the production of metabolites, dietary supplement was more efficient in reducing the ammonia content and probiotic ice cream was shown to release more acetate, propionate and butyrate fatty acids. Thus, each of the supplementation forms evaluated had specific advantages and could be considered as an alternative to diversify probiotic consumption

\section{Acknowledgements}

The authors thank Jaqueline Petitto (State University of Campinas), Fernanda Campos Freire (São Paulo State University - UNESP) and Sofía Lorena Oddi (Universidad Nacional del Litoral) for their assistance. Also, the authors thank the company Neoprospecta Microbiome Technologies for the next-generation sequencing analysis.

This work was supported by the São Paulo Research Foundation (FAPESP) - Project number 2017/25007-9; the Coordenação de Aperfeiçoamento de Pessoal de Nível Superior - Brasil (CAPES) Finance Code 001; and the Fundo de Apoio ao Ensino, à Pesquisa e Extensão (FAEPEX) - Number 519.292. None of the funders had a role in the design, analysis or writing of this article.

V. C. C. R.: master's degree student involved with the design of the study, all the analysis (except the next-generation sequencing of the microbiota and the bioinformatics analysis), analysing the data and writing the article; A. L. R. F. D.: in vitro experimental setup and ammonium ions analysis; L. C. F.: ice cream production and analysis and real-time quantitative PCR analysis; F. M. S.: realtime quantitative PCR and data analysis; A. S.: SCFA analysis; L. C.: bioinformatics analysis; M. F. N.: bioinformatics analysis; K. S. design of the in vitro experiment and data analysis; A. E. C. A.: design of the study, coordination of the research, analysing of the data and writing the article. All the authors contributed and agreed with the final version of the article.

The authors declare that there are no conflicts of interest.

\section{Supplementary material}

For supplementary material referred to in this article, please visit https://doi.org/10.1017/S0007114520000896

\section{References}

1. Cani PD (2018) Human gut microbiome: hopes, threats and promises. Gut 67, 1716-1725.

2. Rinninella E, Raoul P, Cintoni M, et al. (2019) What is the healthy gut microbiota composition? A changing ecosystem across age, environment, diet, and diseases. Microorganisms 7, E14.

3. Natividad JMM \& Verdu EF (2013) Modulation of intestinal barrier by intestinal microbiota: pathological and therapeutic implications. Pharmacol Res 69, 42-51.

4. Khosravi A \& Mazmanian SK (2013) Disruption of the gut microbiome as a risk factor for microbial infections. Curr Opin Microbiol 16, 221-227.
5. Doré J, Simrén M, Buttle L, et al. (2013) Hot topics in gut microbiota. United European Gastroenterol J 1, 311-318.

6. Bäumler AJ \& Sperandio V (2016) Interactions between the microbiota and pathogenic bacteria in the gut. Nature $\mathbf{5 3 5}$, 85-93.

7. Den Besten G, Van Eunen K, Groen AK, et al. (2013) The role of short-chain fatty acids in the interplay between diet, gut microbiota, and host energy metabolism. J Lipid Res $\mathbf{5 4}$, $2325-2340$.

8. Gensollen T, Iyer SS, Kasper DL, et al. (2016) How colonization by microbiota in early life shapes the immune system. Science 352, 539-544.

9. Schmidt TSB, Raes J \& Bork P (2018) The human gut microbiome: from association to modulation. Cell 172, 1198-1215.

10. Gibson GR \& Roberfroid MB (1995) Dietary modulation of the human colonic microflora: introducing the concept of prebiotics. J Nutr 125, 1401-1412.

11. Bron PA, Van Baarlen P \& Kleerebezem M (2012) Emerging molecular insights into the interaction between probiotics and the host intestinal mucosa. Nat Rev Microbiol 10, 66-78.

12. Hemaiswarya S, Raja R, Ravikumar R, et al. (2013) Mechanism of action of probiotics. Braz Arch Biol Technol 56, 113-119.

13. O'Flaherty S, Saulnier DM, Pot B, et al. (2010) How can probiotics and prebiotics impact mucosal immunity? Gut Microbes 1, 293-300.

14. Gerritsen J, Smidt H, Rijkers GT, et al. (2011) Intestinal microbiota in human health and disease: the impact of probiotics. Genes Nutr 6, 209-240.

15. Ranadheera RDCS, Baines SK \& Adams MC (2010) Importance of food in probiotic efficacy. Food Res Int 43, 1-7.

16. Sanders ME \& Marco ML (2010) Food formats for effective delivery of probiotics. Annu Rev Food Sci Technol 1, 65-85.

17. Saad N, Delattre C, Urdaci M, et al. (2013) An overview of the last advances in probiotic and prebiotic field. LWT Food Sci Technol 50, 1-16.

18. Kotarski SF \& Savage DC (1979) Models for study of the specificity by which indigenous lactobacilli adhere to murine gastric epithelia. Infect Immun 26, 966-975.

19. Guarner F \& Malagelada JR (2003) Gut flora in health and disease. Lancet 361, 512-519.

20. Nader-Macías MEF \& Tomás MSJ (2015) Profiles and technological requirements of urogenital probiotics. Adv Drug Deliv Rev 92, 84-104.

21. Cruz AG, Antunes AEC, Sousa ALOP, et al. (2009) Ice-cream as a probiotic food carrier. Food Res Int 42, 1233-1239.

22. Hill C, Guarner F, Reid G, et al. (2014) The international scientific association for probiotics and prebiotics consensus statement on the scope and appropriate use of the term probiotic. Nat Rev Gastroenterol Hepatol 11, 506-514.

23. Ministério da Saúde, Brazil (Health Ministry, Brazil) (2003) Resolução RDC n. 359, de 23 de dezembro de 2003 (Resolution RDC no. 359, 23 December 2003). Aprova Regulamento Técnico de Porções de Alimentos Embalados para Fins de Rotulagem Nutricional (Approves technical regulation of portions of packaged foods for nutrition labeling). http:// portal.anvisa.gov.br/documents/33880/2568070/res0359_ 23_12_2003.pdf/76676765-a107-40d9-bb34-5f05ae897bf3 (accessed January 2019).

24. Ministério da Saúde, Brazil (Health Ministry, Brazil) (2018) Resolução RDC n. 243, de 26 de julho de 2018 (Resolution RDC no. 243, 26 July 2018). Dispõe sobre os requisitos sanitários dos suplementos alimentares (Provides for the health requirements of food supplements). http://www.in.gov.br/ materia/-/asset_publisher/Kujrw0TZC2Mb/content/id/34379969/ do1-2018-07-27-resolucao-da-diretoria-colegiada-rdc-n-243-de26-de-julho-de-2018-34379917 (accessed January 2019). 
25. Van de Wiele T, Boon N, Possemiers S, et al. (2004) Prebiotic effects of chicory inulin in the simulator of the human intestinal microbial ecosystem. FEMS Microbiol Ecol 51, $143-153$.

26. Marzorati M, Qin B, Hildebrand F, et al. (2015) Addition of acacia gum to a FOS/inulin blend improves its fermentation profile in the Simulator of the Human Intestinal Microbial Ecosystem (SHIME ${ }^{\circledR}$ ). J Funct Foods 16, 211-222.

27. Verhoeckx K, Cotter P, López-Expósito I, et al. (2015) In vitro fermentation models: general introduction. In The Impact of Food Bio-Actives on Gut Health: In Vitro and Ex Vivo Model, pp. 275-279 [K Verhoeckx, P Cotter, I López-Expósito, et al., editors]. London: Springer.

28. Aura A-M \& Maukonen J (2015) One compartment fermentation model. In The Impact of Food Bio-Actives on Gut Health: In Vitro and Ex Vivo Models, pp. 281-292 [K Verhoeckx, P Cotter, I López-Expósito, et al., editors]. London: Springer.

29. Venema K (2015) The TNO In Vitro Model of the colon (TIM2). In The Impact of Food Bio-Actives on Gut Health: In Vitro and Ex Vivo Model, pp. 293-304 [K Verhoeckx, P Cotter, I López-Expósito, et al., editors]. London: Springer.

30. Van de Wiele T, Van den Abbeele P, Ossieur W, et al. (2015) The Simulator of the Human Intestinal Microbial Ecosystem (SHIME ${ }^{\circledR}$ ). In The Impact of Food Bio-Actives on Gut Health: In Vitro and Ex Vivo Model, pp. 305-317 [K Verhoeckx, $\mathrm{P}$ Cotter, I López-Expósito, et al., editors]. London: Springer.

31. Barroso E, Cueva C, Peláez C, et al. (2015) The computercontrolled multicompartmental dynamic model of the gastrointestinal system SIMGI. In The Impact of Food Bio-Actives on Gut Health: In Vitro and Ex Vivo Model, pp. 319-327 [K Verhoeckx, P Cotter, I López-Expósito, et al., editors]. London: Springer.

32. Possemiers S, Marzorati M, Verstraete W, et al. (2010) Bacteria and chocolate: a successful combination for probiotic delivery. Int J Food Microbiol 141, 97-103.

33. Rodrigues VCC, Silva LGS, Simabuco FM, et al. (2019) Survival, metabolic status and cellular morphology of probiotics in dairy products and dietary supplement after simulated digestion. J Funct Foods 55, 126-134.

34. Magariños H, Selaive S, Costa M, et al. (2007) Viability of probiotic micro-organisms (Lactobacillus acidophilus La-5 and Bifidobacterium animalis subsp. lactis Bb-12) in ice cream. Int J Dairy Technol 60, 128-134.

35. Instituto Adolfo Lutz (IAL) (2008) Métodos físico-químicos para análise de alimentos (Physico-chemical Methods for Food Analysis), 4th ed. São Paulo: Instituto Adolfo Lutz.

36. Association of Official Analytical Chemists (AOAC) (2012) Official Methods of Analysis of the Association of Official Analytical Chemists, 19th ed. Gaithersburg, MD: AOAC International.

37. Association of Official Analytical Chemists (AOAC) (1996) Official method 989.05 fat in milk modified Mojonnier: ether extraction method (first action 1989 and final action 1992). J AOAC Int 71, 898.

38. Molly K, Woestyne MV, De Smet I, et al. (1994) Validation of the Simulator of the Human Intestinal Microbial Ecosystem (SHIME) reactor using microorganism-associated activities. Microbiol Ecol Health Dis 7, 191-200.

39. Possemiers S, Verthé K, Uyttendaele S, et al. (2004) PCR-DGGE-based quantification of stability of the microbial community in a simulator of the human intestinal microbial ecosystem. FEMS Microbiol Ecol 49, 495-507.

40. Duque ALRF, Monteiro M, Adorno MAT, et al. (2016) An exploratory study on the influence of orange juice on gut microbiota using a dynamic colonic model. Food Res Int 84 , 160-169.

41. van de Wiele T, Boon N, Possemiers S, et al. (2007) Inulin-type fructans of longer degree of polymerization exert more pronounced in vitro prebiotic effects. J Appl Microbiol 102, 452-460

42. Bianchi F, Rossi EA, Sakamoto IK, et al. (2014) Beneficial effects of fermented vegetal beverages on human gastrointestinal microbial ecosystem in a simulator. Food Res Int 64, 43-52.

43. Possemiers S, Bolca S, Grootaert C, et al. (2006) The prenylflavonoid isoxanthohumol from hops (Humulus lupulus L.) is activated into the potent phytoestrogen 8-prenylnaringenin in vitro and in the human intestine. J Nutr 136, 1862-1867.

44. Herbel SR, Lauzat B, von Nickisch-Rosenegk M, et al. (2013) Species-specific quantification of probiotic lactobacilli in yoghurt by quantitative real-time PCR. J Appl Microbiol 115, 1402-1410.

45. Junick J \& Blaut M (2012) Quantification of human fecal Bifidobacterium species by use of quantitative real-time PCR analysis targeting the groEL gene. Appl Environ Microbiol 78, 2613-2622.

46. Wang Y \& Qian PY (2009) Conservative fragments in bacterial 16S rRNA genes and primer design for 16S ribosomal DNA amplicons in metagenomic studies. PLOS ONE $\mathbf{4}$, e7401.

47. Caporaso JG, Lauber CL, Walters WA, et al. (2011) Global patterns of $16 \mathrm{~S}$ rRNA diversity at a depth of millions of sequences per sample. PNAS 108, 4516-4522.

48. Christoff AP, Sereia AFR, Boberg DR, et al. (2017) Bacterial identification through accurate library preparation and high-throughput sequencing [white paper: Bacterial NGS Sequencing]. Neoprospecta Microbiome Technologies.

49. Edgar RC, Haas BJ, Clemente JC, et al. (2011) UCHIME improves sensitivity and speed of chimera detection. Bioinformatics 27, 2194-2200.

50. Caporaso JG, Kuczynski J, Stombaugh J, et al. (2010) QIIME allows analysis of high-throughput community sequencing data. Nat Methods 7, 335-336.

51. Edgar RC (2010) Search and clustering orders of magnitude faster than BLAST. Bioinformatics 26, 2460-2461.

52. McDonald D, Price MN, Goodrich J, et al. (2012) An improved Greengenes taxonomy with explicit ranks for ecological and evolutionary analyses of bacteria and archaea. ISME J 6. 610-618.

53. Wang Q, Garrity GM, Tiedje JM, et al. (2007) Naïve Bayesian classifier for rapid assignment of rRNA sequences into the new bacterial taxonomy. Appl Environ Microbiol 73, 5261-5267.

54. Caporaso JG, Bittinger K, Bushman FD, et al. (2010b) PyNAST: a flexible tool for aligning sequences to a template alignment. Bioinformatics 26, 266-267.

55. Chao A \& Bunge J (2002) Estimating the number of species in a stochastic abundance model. Biometrics 58, 531-539.

56. Shannon CE (1948) A mathematical theory of communication. Bell Syst Tech J 27, 379-423.

57. Hamady M, Lozupone C \& Knight R (2010) Fast UniFrac: facilitating high-throughput phylogenetic analyses of microbial communities including analysis of pyrosequencing and PhyloChip data. ISME J 4, 17-27.

58. Lozupone C \& Knight R (2005) UniFrac: a new phylogenetic method for comparing microbial communities. Appl Environ Microbiol 71, 8228-8235.

59. Agência Nacional de Vigilância Sanitária (ANVISA) (Brazilian Health Regulatory Agency) (2000) Regulamento técnico para fixação de identidade e qualidade de gelados comestíveis, preparados, pós para o preparo e bases para gelados 
comestiveis (Technical regulation for the identity and quality setting of edible ice cream, prepared, preparation powders and edible ice cream bases).

60. Verbeke KA, Boobis AR, Chiodini A, et al. (2015) Towards microbial fermentation metabolites as markers for health benefits of prebiotics. Nutr Res $\mathbf{2 8}, 42-66$.

61. Duysburgh C, Van den Abbeele P, Krishnan K, et al. (2019) A synbiotic concept containing spore-forming Bacillus strains and a prebiotic fiber blend consistently enhanced metabolic activity by modulation of the gut microbiome in vitro. Int $J$ Pharm X 1, 100021.

62. Wang M, Wichienchot S, He X, et al. (2019) In vitro colonic fermentation of dietary fibers: fermentation rate, short-chain fatty acid production and changes in microbiota. Trends Food Sci Technol 88, 1-9.

63. Yang J, Martínez I, Walter J, et al. (2013) In vitro characterization of the impact of selected dietary fibers on fecal microbiota composition and short chain fatty acid production. Anaerobe 23, 74-81.

64. Huda-Faujan N, Abdulamir AS, Fatimah AB, et al. (2010) The impact of the level of the intestinal short chain fatty acids in inflammatory bowel disease patients versus healthy subjects. Open Biochem J 4, 53-58.

65. Böttcher MF, Nordin EK, Sandin A, et al. (2000) Microfloraassociated characteristics in faeces from allergic and nonallergic infants. Clin Exp Allergy 30, 1590-1596.

66. Hijova E \& Chmelarova A (2007) Short chain fatty acids and colonic health. Bratisl Lek Listy 108, 354-358.

67. Feng W, Ao H \& Peng C (2018) Gut microbiota, short-chain fatty acids, and herbal medicines. Front Pharmacol 9, 1-12.

68. Chaikham P \& Rattanasena P (2017) Combined effects of low-fat ice cream supplemented with probiotics on colon microfloral communities and their metabolites during fermentation in a human gut reactor. Food Biosci 17, 35-41.

69. Topping DL \& Clifton PM (2001) Short-chain fatty acids and human colonic function: roles of resistant starch and non starch polysaccharides. Physiol Rev 81, 1031-1064.

70. Macfarlane S \& Macfarlane GT (2003) Regulation of shortchain fatty acid production. Proc Nutr Soc 62, 67-72.

71. McNeil NI, Cummings JH \& James WPT (1978) Short chain fatty acid absorption by the human large intestine. Gut 19, 819-822.

72. Moens F, Van den Abbeele P, Basit AW, et al. (2019) A fourstrain probiotic exerts positive immunomodulatory effects by enhancing colonic butyrate production in vitro. Int J Pharm 555, 1-10.

73. Venegas DP, De la Fuente MK, Landskron G, et al. (2019) Short chain fatty acids (SCFAs)-mediated gut epithelial and immune regulation and its relevance for inflammatory bowel diseases. Front Immunol 10, 277.

74. Macfarlane GT \& Gibson GR (1994) Metabolic activities of the normal colonic flora. In Human Health: The Contribution of Microorganisms, pp. 17-52 [SAW Gibson, editor]. London: Springer.

75. Hu G-X, Chen G-R, Xu H, et al. (2010) Activation of the AMP activated protein kinase by short-chain fatty acids is the main mechanism underlying the beneficial effect of a high fiber diet on the metabolic syndrome. Med Hypotheses $\mathbf{7 4}$, 123-126.

76. Blouin J-M, Penot G, Collinet M, et al. (2011) Butyrate elicits a metabolic switch in human colon cancer cells by targeting the pyruvate dehydrogenase complex. Int J Cancer $\mathbf{1 2 8}$, 2591-2601.

77. Macfarlane GT \& Macfarlane S (2012) Bacteria, colonic fermentation, and gastrointestinal health. J AOAC Int 95, $50-60$.
78. Ríos-Covián D, Ruas-Madiedo P, Margolles A, et al. (2016) Intestinal short chain fatty acids and their link with diet and human health. Front Microbiol 7, 185.

79. Windey K, De Preter V \& Verbeke K (2011) Relevance of protein fermentation to gut health. Mol Nutr Food Res 56, 184-196.

80. Allsopp P, Possemiers S, Campbell D, et al. (2013) An exploratory study into the putative prebiotic activity of fructans isolated from Agave angustifolia and the associated anticancer activity. Anaerobe 22, 38-44.

81. Terpend K, Possemiers S, Daguet D, et al. (2013) Arabinogalactan and fructo-oligosaccharides have a different fermentation profile in the Simulator of the Human Intestinal Microbial Ecosystem (SHIME ${ }^{\circledR}$ ). Environ Microbiol Rep 5, 595-603.

82. Montalto M, D'Onofrio F, Gallo A, et al. (2009) Intestinal microbiota and its functions. Dig Liver Dis 3, 30-34.

83. Scott KP, Gratz SW, Sheridan PO, et al. (2013) The influence of diet on the gut microbiota. Pharmacol Res 69, 52-60.

84. Andriamihaja M, Davila A-M, Eklou-Lawson M, et al. (2010) Colon luminal content and epithelial cell morphology are markedly modified in rats fed with a high-protein diet. $A m J$ Physiol Gastrointest Liver Physiol 299, G1030-G1037.

85. Dominika Ś, Arjan N, Karyn RP, et al. (2011) The study on the impact of glycated pea proteins on human intestinal bacteria. Int J Food Microbiol 145, 267-272.

86. Davila A-M, Blachier F, Gotteland M, et al. (2013) Intestinal luminal nitrogen metabolism: role of the gut microbiota and consequences for the host. Pharmacol Res 68, 95-107.

87. Watanabe A, Sakai T, Sato S, et al. (1997) Clinical efficacy of lactulose in cirrhotic patients with and without subclinical hepatic encephalopathy. Hepatology 26, 1410-1414.

88. Sharma BC, Sharma P, Agrawal A, et al. (2009) Secondary prophylaxis of hepatic encephalopathy: an open-label randomized controlled trial of lactulose versus placebo. Gastroenterology 137, 885-891.

89. Hamer HM, De Preter V, Windey K, et al. (2012) Functional analysis of colonic bacterial metabolism: relevant to health? Am J Physiol Gastrointest Liver Physiol 302, G1-G9.

90. Rochet V, Rigottier-Gois L, Ledaire A, et al. (2008) Survival of Bifidobacterium animalis DN-173010 in the faecal microbiota after administration in lyophilised form or in fermented product - a randomised study in healthy adults. $J$ Mol Microbiol Biotechnol 14, 128-136.

91. Breban M (2016) Gut microbiota and inflammatory joint diseases. Joint Bone Spine 83, 645-649.

92. Unno T, Choi J-H, Hur H-G, et al. (2015) Changes in human gut microbiota influenced by probiotic fermented milk ingestion. J Dairy Sci 98, 3568-3576.

93. Rettedal EA, Altermann E, Roy NC, et al. (2019) The effects of unfermented and fermented cow and sheep milk on the gut microbiota. Front Microbiol 10, 458.

94. Saarela MH (2019) Safety aspects of next generation probiotics. Curr Opin Food Sci 30, 8-13.

95. Tap J, Mondot S, Levenez F, et al. (2009) Towards the human intestinal microbiota phylogenetic core. Environ Microbiol 11, 2574-2584.

96. Tap J, Derrien M, Törnblom H, et al. (2017) Identification of an intestinal microbiota signature associated with severity of irritable bowel syndrome. Gastroenterology $\mathbf{1 5 2}$, 111-123.

97. Manichanh C, Rigottier-Gois L, Bonnaud E, et al. (2006) Reduced diversity of faecal microbiota in Crohn's disease revealed by a metagenomic approach. Gut 55, 205-211.

98. Sokol H, Pigneur B, Watterlot L, et al. (2008) Faecalibacterium prausnitzii is an anti-inflammatory commensal bacterium 
identified by gut microbiota analysis of Crohn disease patients. Proc Natl Acad Sci U S A 105, 16731-16736.

99. Zhang M, Qiu X, Zhang H, et al. (2014) Faecalibacterium prausnitzii inhibits interleukin-17 to ameliorate colorectal colitis in rats. PLOS ONE 9, e109146.

100. Pittayanon R, Lau JT, Yuan Y, et al. (2019) Gut microbiota in patients with irritable bowel syndrome - a systematic review. Gastroenterology 157, 97-108.

101. Lopez-Siles M, Duncan SH, Garcia-Gil LJ, et al. (2017) Faecalibacterium prausnitzii: from microbiology to diagnostics and prognostics. ISME J 11, 841-852.

102. Duncan SH, Hold GL, Harmsen HJM, et al. (2002) Growth requirements and fermentation products of Fusobacterium prausnitzii, and a proposal to reclassify it as Faecalibacterium prausnitzii gen. nov., comb. nov. Int J Syst Evol Microbiol 52, 2141-2146.

103. Rivière A, Selak M, Lantin D, et al. (2016) Bifidobacteria and butyrate-producing colon bacteria: importance and strategies for their stimulation in the human gut. Front Microbiol 7, 979.

104. Fujimoto T, Imaeda H, Takahashi K, et al. (2013) Decreased abundance of Faecalibacterium prausnitzii in the gut microbiota of Crohn's disease. J Gastroenterol Hepatol 28, 613-619.

105. Martín R, Miquel S, Chain F, et al. (2015) Faecalibacterium prausnitzii prevents physiological damages in a chronic low-grade inflammation murine model. BMC Microbiol 15, 67

106. Zhang X, Shen D, Fang Z, et al. (2013) Human gut microbiota changes reveal the progression of glucose intolerance. PLOS ONE 8, e 71108 .

107. Bervoets L, Van Hoorenbeeck K, Kortleven I, et al. (2013) Differences in gut microbiota composition between obese and lean children: a cross-sectional study. Gut Pathog 5, 10.
108. Jiang H, Ling Z, Zhang Y, et al. (2015) Altered fecal microbiota composition in patients with major depressive disorder. Brain Behav Immun 48, 186-194.

109. Zhuang Z-Q, Shen L-L, Li W-W, et al. (2018) Gut microbiota is altered in patients with Alzheimer's disease. J Alzheimers Dis 63, 1337-1346.

110. O'Toole PW, Marchesi JR \& Hill C (2017) Next-generation probiotics: the spectrum from probiotics to live biotherapeutics. Nat Microbiol 2, 17057.

111. Hsiao EY, McBride SW, Hsien S, et al. (2013) The microbiota modulates gut physiology and behavioral abnormalities associated with autism. Cell 155, 1451-1463.

112. Lee MY, Kim YJ, Gu HJ, et al. (2016) A case of bacteremia caused by Dialister pneumosintes and Slackia exigua in a patient with periapical abscess. Anaerobe 38, 36-38.

113. Tito RY, Cypers H, Joossens M, et al. (2017) Dialister as a microbial marker of disease activity in spondyloarthritis. Arthritis Rheum 69, 114-121.

114. Valles-Colomer M, Falony G, Darzi Y, et al. (2019) The neuroactive potential of the human gut microbiota in quality of life and depression. Nat Microbiol 4, 623-632.

115. Dinan TG, Stanton C \& Cryan JF (2013) Psychobiotics: a novel class of psychotropic. Biol Psychiatry 74, 720-726.

116. Takada M, Nishida K, Kataoka-Kato A, et al. (2016) Probiotic Lactobacillus casei strain Shirota relieves stress-associated symptoms by modulating the gut - brain interaction in human and animal models. Neurogastroenterol Motil 28, $1027-1036$.

117. Slykerman RF, Hood F, Wickens K, et al. (2017) Effect of Lactobacillus rhamnosus HN001 in pregnancy on postpartum symptoms of depression and anxiety: a randomised double-blind placebo-controlled trial. EBioMedicine 24, 159-165. 